\title{
Incidence and frequency of cancer cachexia during chemotherapy for advanced pancreatic ductal adenocarcinoma
}

\author{
Shuichi Mitsunaga ${ }^{1,2}$ (1) $\cdot$ Eiji Kasamatsu $^{3} \cdot$ Koji Machii $^{3}$
}

Received: 28 November 2019 / Accepted: 2 February 2020 / Published online: 26 February 2020

(C) The Author(s) 2020

\begin{abstract}
Purpose Cachexia influences the patient's physical wellbeing and quality of life, and the patient's ability to tolerate their cancer therapies, especially cytotoxic chemotherapy. The purpose of this study was to investigate the frequency and timing of onset of cancer cachexia during chemotherapy and its association with prognosis and toxicity in patients with pancreatic ductal adenocarcinoma (PDAC).

Methods We performed a retrospective study in patients who underwent first-line chemotherapy after diagnosis of advanced PDAC between 6 June 2008 and 31 March 2017. Base cachexia (weight loss up to 6 months before starting first-line chemotherapy) and follow-up cachexia (after starting first-line chemotherapy) were defined as weight loss $>2 \%$ with a body mass index (BMI) $<20 \mathrm{~kg} / \mathrm{m}^{2}$ or weight loss $>5 \%$.

Results A total of 150 patients were registered. The median age and BMI were 65 years and $21.7 \mathrm{~kg} / \mathrm{m}^{2}$, respectively. Base cachexia occurred in 50\% of patients. Follow-up cachexia occurred in 32\% within 12 weeks of starting first-line chemotherapy, reaching $64 \%$ at 1 year. Overall survival was not significantly different between patients with and without follow-up cachexia, regardless of whether cancer cachexia occurred within 12, 24, or 48 weeks of starting first-line treatment. Appetite loss, fatigue, nausea, and diarrhea were more frequent in patients with follow-up cachexia than in those without follow-up cachexia.

Conclusion Follow-up cachexia had an early onset, but was not a prognostic factor for overall survival in patients with PDAC. Some adverse events tended to be more frequent in patients with follow-up cachexia than in those without follow-up cachexia.
\end{abstract}

Keywords Cachexia $\cdot$ Incidence $\cdot$ Survival $\cdot$ Pancreatic cancer $\cdot$ Adverse events

\section{Introduction}

Cancer cachexia is a multi-factorial metabolic syndrome characterized by ongoing loss of skeletal muscle mass that cannot be fully reversed by conventional nutritional support and leads

Electronic supplementary material The online version of this article (https://doi.org/10.1007/s00520-020-05346-8) contains supplementary material, which is available to authorized users.

Shuichi Mitsunaga smitsuna@east.ncc.go.jp

1 Department of Hepatobiliary and Pancreatic Oncology, National Cancer Center, National Cancer Center Hospital East, 6-5-1, Kashiwanoha, Kashiwa, Chiba 277-8577, Japan

2 Division of Biomarker Discovery, Exploratory Oncology Research \& Clinical Trial Center, National Cancer Center, Chiba, Japan

3 Medical Affairs Department, Ono Pharmaceutical Co., Ltd, Osaka, Japan to progressive functional impairment. Its pathophysiology is characterized by a hypercatabolic state driven by reduced food intake and abnormal metabolism [1]. It is now becoming clear that cancer cachexia has an impact on the patient's physical wellbeing and quality of life, and the patient's ability to tolerate their cancer therapies, especially cytotoxic chemotherapy [2-6]. The definitions of cancer cachexia and the diagnostic criteria differed between trials in the past [7, 8]. In 2011, the European Palliative Care Research Collaborative (EPCRC) proposed the definition of cancer cachexia, as (a) weight loss $>5 \%$ over the past 6 months, (b) weight loss of $>2 \%$ and body mass index $(\mathrm{BMI})<20 \mathrm{~kg} / \mathrm{m}^{2}$, or (c) weight loss of $>2 \%$ and diagnosis of sarcopenia [1]. The EPCRC definition has now been accepted as the current consensus of cancer cachexia.

In a study of untreated non-small cell lung cancer (NSCLC) patients with a 52-week observation period, weight loss of $\geq 5 \%$ was observed in $\geq 20 \%$ of registered patients, and weight loss was associated with decreases in Karnofsky 
performance scale and quality of life, and with shortened survival [9]. In a study of pancreatic ductal adenocarcinoma (PDAC), the incidence of base cachexia, defined as weight loss $>5 \%$ over up to 6 months prior to diagnosis, was $63 \%$ and base cachexia was found to be a prognostic factor for reduced overall survival (OS) [10]. In a study of several types of cancer that assessed cachexia during chemotherapy of 191 patients, unintentional weight loss was reported in over $63 \%$ of patients, with weight loss of $\geq 5 \%$ and $\geq 10 \%$ in $38.7 \%$ and $24.6 \%$, respectively, and weight loss was associated with gastrointestinal symptoms [11]. Despite these findings, very few reports have described the frequency or prognosis of cachexia during cancer treatment, and none have focused on PDAC. Therefore, we performed this retrospective study in order to evaluate the frequency and timing of onset of EPCRC-based cachexia during chemotherapy and its association with prognosis or associated toxicities. These data will be valuable for the management of patients with advanced PDAC.

\section{Methods}

\section{Ethics}

This study was approved by the ethics review committee of the National Cancer Center Hospital East (reference 2018148). This study was registered on the University Hospital Medical Information Network-Clinical Trials Registry (UMIN000034972).

\section{Patients}

The medical records database was searched to retrieve the records of patients who were clinically and pathologically diagnosed with advanced PDAC and who underwent firstline systemic chemotherapy between 6 June 2008 and 31 March 2017 at the National Cancer Center Hospital East.

\section{Definition of cancer cachexia}

In this study, we defined cancer cachexia as either weight loss $>5 \%$ or weight loss $>2 \%$ with a BMI $<20 \mathrm{~kg} / \mathrm{m}^{2}$. Base cachexia was defined as weight loss within 6 months before the start of chemotherapy. Follow-up cachexia was defined as cachexia that occurred after the start of first-line systemic chemotherapy, based on the change in body weight from the start of chemotherapy at the following observation times: 1-12, 13-24, 25-36, 37-48, and beyond 48 weeks.

\section{Data collection}

Data on body weight, laboratory tests, and toxicities (Common Terminology Criteria for Adverse Events; CTCAE version 4.0)
[12] were collected at the start of chemotherapy ( 0 weeks). The latest body weight, laboratory test data, and worst $\mathrm{AE}$ data were collected in 4-week periods in the observation time. The greatest body weight up to 6 months before the start of chemotherapy was also collected.

\section{Data analyses}

The primary endpoints were the timing of cachexia onset (1-12, 13-24, 25-36, 37-48, and beyond 48 weeks) and the cumulative incidence of follow-up cachexia from the start of first-line chemotherapy to 156 weeks. The cumulative incidence of follow-up cachexia was calculated as the number of new episodes of follow-up cachexia without considering death as a competing risk.

Secondary endpoints were the associations between follow-up cachexia and the frequency of adverse events (AEs), OS, treatment status, and laboratory variables. AEs were categorized using CTCAE version 4.0 of the National Cancer Institute [12].

OS was calculated from the beginning of first-line chemotherapy. Survival curves were drawn using the Kaplan-Meier method. OS was compared using the log-rank test between patients who developed follow-up cachexia within 12, 24, and 48 weeks of starting first-line chemotherapy and patients who did not develop follow-up cachexia. Survival curves were also drawn by landmark analyses at 12,24 , and 48 weeks.

We originally planned to analyze data according to the presence or absence of follow-up cachexia within 48 weeks of starting first-line treatment. Owing to the disparity in the number of patients, we also performed exploratory analyses in which patients were divided according to whether they experienced follow-up cachexia within 12 weeks or 24 weeks of starting first-line chemotherapy.

Hazard ratios (HR) with 95\% confidence intervals (CI) according to the presence or absence of follow-up cancer cachexia for OS were evaluated using the Cox proportional hazard model with or without adjustment for age, sex, multidrug therapy, Eastern Cooperative Oncology Group (ECOG) performance status, Union for International Cancer Control (UICC) stage, C-reactive protein (CRP), base cachexia, and carbohydrate antigen 19-9 (CA19-9). The cut-off period for the occurrence of follow-up cachexia was set at 24 weeks because the numbers of patients with and without cachexia by this time-point were similar.

Median survival times were calculated with $95 \%$ confidence intervals $(\mathrm{CI})$, which were determined using the Brookmeyer and Crowley method.

All $P$ values were two-sided, and $P<0.05$ was considered statistically significant. Data analyses were performed using SAS for Windows version 9.4 or later (SAS Institute, Cary, NC, USA). 
Table 1 Patient characteristics

\begin{tabular}{|c|c|}
\hline & Value \\
\hline$N$ & 150 \\
\hline \multicolumn{2}{|l|}{ Sex } \\
\hline Male & $88(58.7 \%)$ \\
\hline Female & $62(41.3 \%)$ \\
\hline Age, years & $65(35-83)$ \\
\hline BMI, $\mathrm{kg} / \mathrm{m}^{2}$ & $21.7(13.8-33.3)$ \\
\hline ECOG PS & $0(0-1)$ \\
\hline 0 & $106(70.7 \%)$ \\
\hline 1 & $44(29.3 \%)$ \\
\hline \multicolumn{2}{|l|}{ Primary site } \\
\hline Pancreatic head & $60(40.0 \%)$ \\
\hline Pancreatic body & $63(42.0 \%)$ \\
\hline Pancreatic tail & $27(18.0 \%)$ \\
\hline \multicolumn{2}{|l|}{ UICC stage } \\
\hline III & $44(29.3 \%)$ \\
\hline IV & $106(70.7 \%)$ \\
\hline \multicolumn{2}{|l|}{ Modified Glasgow prognosis score ${ }^{\mathrm{a}}$} \\
\hline A & $96(64.0 \%)$ \\
\hline $\mathrm{B}$ & $7(4.7 \%)$ \\
\hline $\mathrm{C}$ & $38(25.3 \%)$ \\
\hline $\mathrm{D}$ & $9(6.0 \%)$ \\
\hline \multicolumn{2}{|l|}{ First-line chemotherapy } \\
\hline Modified FOLFIRINOX & $45(30.0 \%)$ \\
\hline Gemcitabine monotherapy & $57(38.0 \%)$ \\
\hline Gemcitabine + nab-paclitaxel & $48(32.0 \%)$ \\
\hline $\begin{array}{l}\text { Cancer cachexia at the start of first-line } \\
\text { chemotherapy (base cachexia), yes } \\
\text { Comorbidities }\end{array}$ & $75(50.0 \%)$ \\
\hline Hypertension & $46(30.7 \%)$ \\
\hline Diabetes mellitus & $38(25.3 \%)$ \\
\hline Dyslipidemia & $9(6.0 \%)$ \\
\hline Other & $22(14.7 \%)$ \\
\hline None & $73(48.7 \%)$ \\
\hline $\mathrm{CrCl}^{\mathrm{b}}, \mathrm{mL} / \mathrm{min}$ & $84.26(36.30-177.05)$ \\
\hline Neutrophil/lymphocyte ratio & $2.95(0.81-12.68)$ \\
\hline CA19-9, U/mL & $747.9(0.2-284,200)$ \\
\hline Sodium, $\mathrm{mmol} / \mathrm{L}$ & $141(131-144)$ \\
\hline Potassium, mmol/L & $4.3(3.4-6.3)$ \\
\hline $\mathrm{AST}, \mathrm{U} / \mathrm{L}$ & $22(11-136)$ \\
\hline ALT, U/L & $23(7-187)$ \\
\hline ALP, U/L & $321(104-2558)$ \\
\hline Cholinesterase, U/L & $268(109-553)$ \\
\hline Total bilirubin, mg/dL & $0.65(0.12-2.20)$ \\
\hline Neutrophil count, cells $/ \mu \mathrm{L}$ & $3805(1510-12,650)$ \\
\hline WBC count, cells $/ \mu \mathrm{L}$ & $5900(2500-16,100)$ \\
\hline Lymphocyte count, cells $/ \mu \mathrm{L}$ & $1310(440-2770)$ \\
\hline Platelet count, $\times 10^{4}$ cells $/ \mu \mathrm{L}$ & $18.6(8.5-52.4)$ \\
\hline Creatinine, mg/dL & $0.66(0.33-1.34)$ \\
\hline Albumin, $\mathrm{g} / \mathrm{dL}$ & $4.0(2.7-4.9)$ \\
\hline
\end{tabular}

Table 1 (continued)

\begin{tabular}{|c|c|}
\hline & Value \\
\hline Total protein, g/dL & $6.9(5.6-8.1)$ \\
\hline $\mathrm{CRP}, \mathrm{mg} / \mathrm{dL}$ & $0.39(0.01-9.94)$ \\
\hline Hemoglobin, g/dL & $12.6(8.1-18.2)$ \\
\hline Glucose, mg/dL & $109(59-350)$ \\
\hline \multicolumn{2}{|c|}{ Values are number (percent) of patients or median (range) } \\
\hline \multicolumn{2}{|c|}{$\begin{array}{l}B M I \text { body mass index, ECOG PS Eastern Cooperative Oncology Group } \\
\text { performance status, UICC Union for International Cancer Control, } C r C l \\
\text { creatinine clearance, } C A 19-9 \text { carbohydrate antigen 19-9, } A S T \text { aspartate } \\
\text { aminotransferase, } A L T \text { alanine aminotransferase, } A L P \text { alkaline phospha- } \\
\text { tase, } W B C \text { white blood cell count, } C R P \text { C-reactive protein }\end{array}$} \\
\hline \multicolumn{2}{|c|}{$\begin{array}{l}\text { a } A=\text { albumin } \geq 3.5 \mathrm{~g} / \mathrm{dL} \text { and } C R P<1.0 \mathrm{mg} / \mathrm{dL} ; B=\text { albumin }<3.5 \mathrm{~g} / \mathrm{dL} \\
\text { and } C R P<1.0 \mathrm{mg} / \mathrm{dL} ; C=\text { albumin } \geq 3.5 \mathrm{~g} / \mathrm{dL} \text { and } C R P \geq 1.0 \mathrm{mg} / \mathrm{dL} \text {; } \\
\mathrm{D}=\text { albumin }<3.5 \mathrm{~g} / \mathrm{dL} \text { and } \mathrm{CRP} \geq 1.0 \mathrm{mg} / \mathrm{dL}\end{array}$} \\
\hline${ }^{\mathrm{b}}$ Cockcroft-Gault fo & \\
\hline
\end{tabular}

\section{Results}

\section{Patients}

A total of 150 patients were identified and included in this study, of which 88 patients $(58.7 \%)$ were male and 62 patients $(41.3 \%)$ were female (Table 1$)$. The median (range) age and BMI were 65 (35-83) years and 21.7
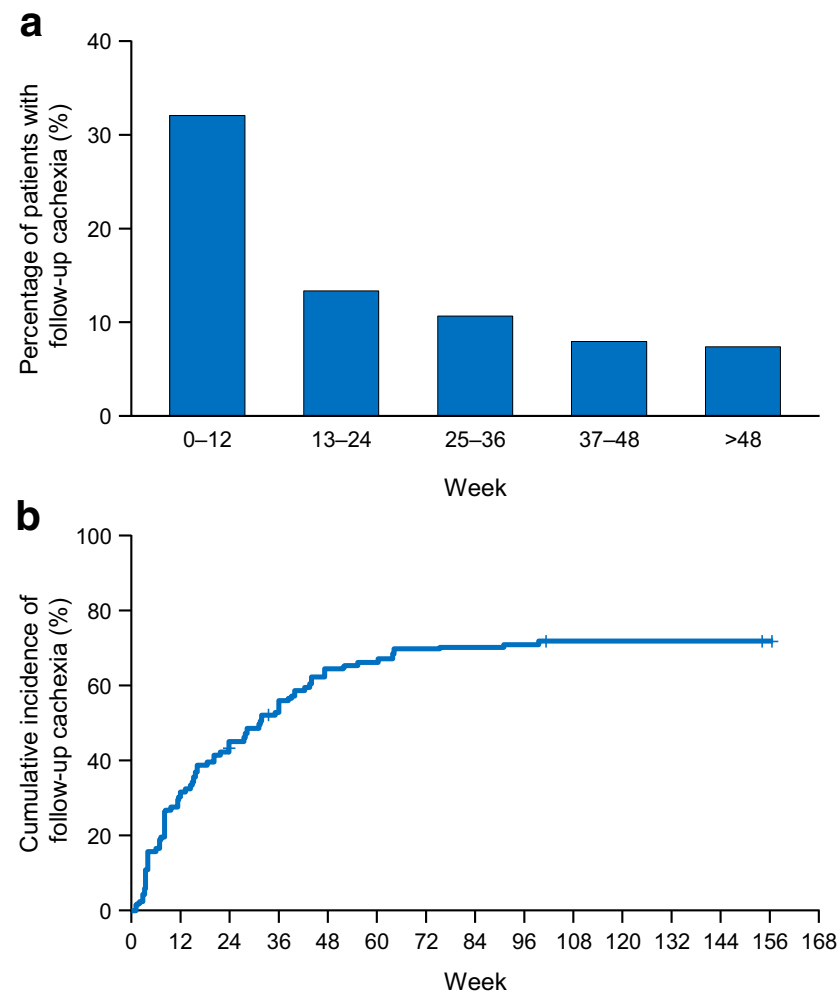

Fig. 1 Timing of onset (a) and cumulative incidence (b) of follow-up cachexia after the start of first-line chemotherapy 


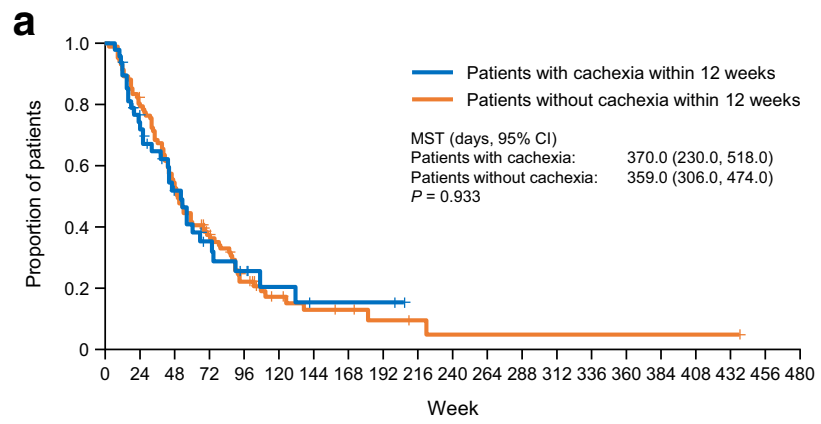

b

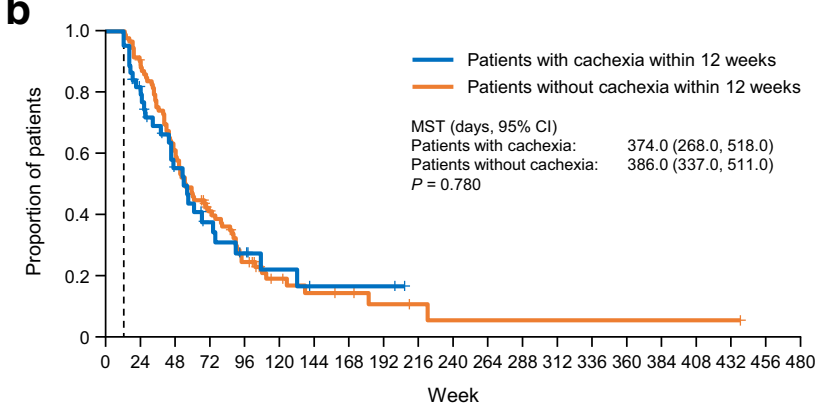

Nat risk
With

$\begin{array}{lllllllllll}\begin{array}{l}\text { With } \\ \text { cachexia }\end{array} & 48 & 32 & 19 & 11 & 7 & 4 & 2 & 2 & 2\end{array}$

$\begin{array}{llllllllllllllllllll}\begin{array}{l}\text { Without } \\ \text { cachexia }\end{array} & 102 & 81 & 56 & 34 & 18 & 9 & 6 & 5 & 3 & 2 & 1 & 1 & 1 & 1 & 1 & 1 & 1 & 1 & 1\end{array}$

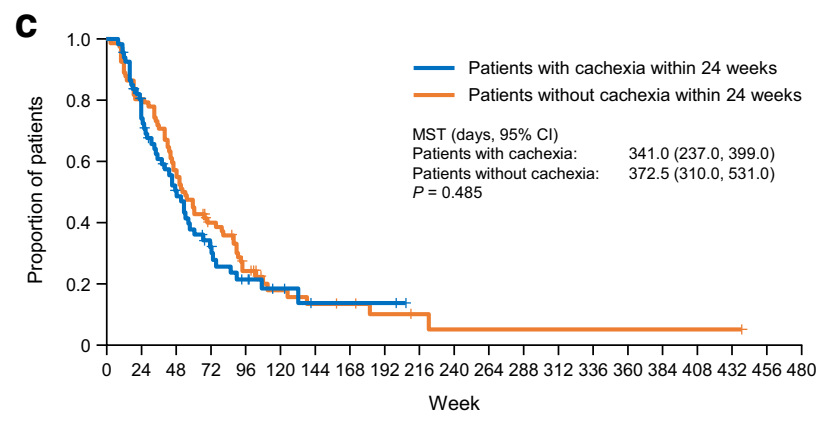

$\mathrm{N}$ at risk
With

$\begin{array}{lllllllllll}\begin{array}{l}\text { With } \\ \text { cachexia }\end{array} & 44 & 32 & 19 & 11 & 7 & 4 & 2 & 2 & 2\end{array}$

$\begin{array}{llllllllllllllllllll}\begin{array}{l}\text { cachexia } \\ \text { Without } \\ \text { cachexia }\end{array} & 93 & 81 & 56 & 34 & 18 & 9 & 6 & 5 & 3 & 2 & 1 & 1 & 1 & 1 & 1 & 1 & 1 & 1 & 1\end{array}$

d

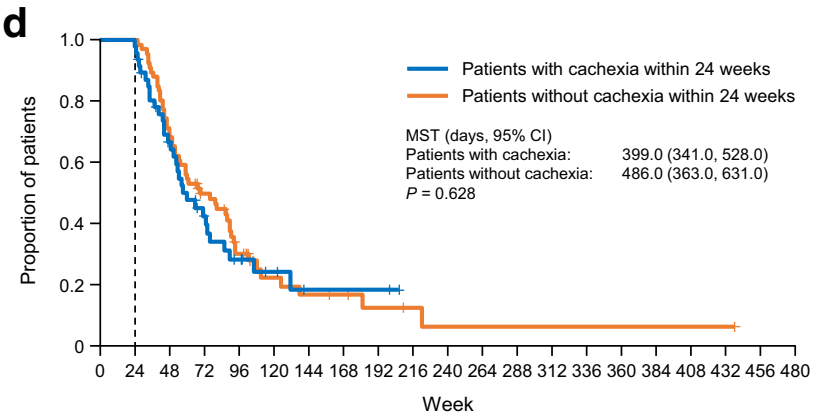

Nat risk

$\begin{array}{llllllllll}\text { With } & 47 & 47 & 28 & 16 & 9 & 5 & 2 & 2 & 2\end{array}$

$\begin{array}{llllllllllllllllllll}\begin{array}{l}\text { Wachexiaut } \\ \text { vithout } \\ \text { cachexia }\end{array} & 66 & 66 & 47 & 29 & 16 & 8 & 6 & 5 & 3 & 2 & 1 & 1 & 1 & 1 & 1 & 1 & 1 & 1 & 1\end{array}$

$\begin{array}{llllllllll}\begin{array}{l}N \text { at risk } \\ \text { With } \\ \text { cachexia }\end{array} & 68 & 47 & 28 & 16 & 9 & 5 & 2 & 2 & 2\end{array}$

$\begin{array}{llllllllllllllllllll}\begin{array}{l}\text { cachexia } \\ \text { Without } \\ \text { cachexia }\end{array} & 82 & 66 & 47 & 29 & 16 & 8 & 6 & 5 & 3 & 2 & 1 & 1 & 1 & 1 & 1 & 1 & 1 & 1 & 1\end{array}$

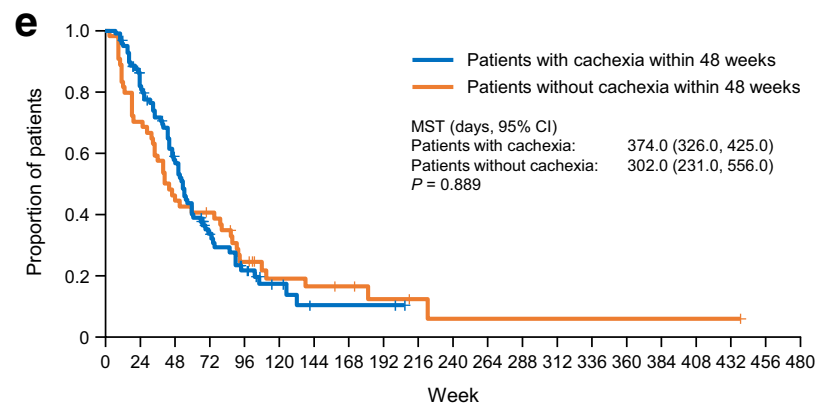

f
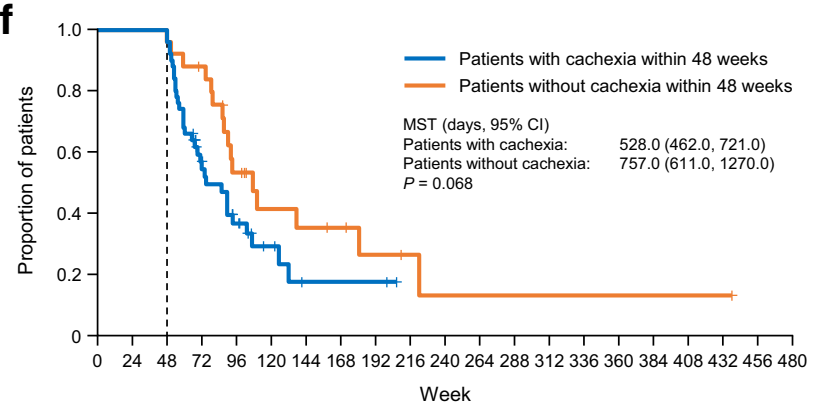

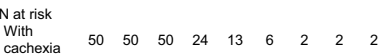

$\begin{array}{llllllllllllllllllll}\begin{array}{l}\text { Without } \\ \text { cachexia }\end{array} & 25 & 25 & 25 & 21 & 12 & 7 & 6 & 5 & 3 & 2 & 1 & 1 & 1 & 1 & 1 & 1 & 1 & 1 & 1\end{array}$

$\begin{array}{llllllllll}\begin{array}{l}\text { Nat risk } \\ \text { With } \\ \text { cachexia }\end{array} & 96 & 75 & 50 & 24 & 13 & 6 & 2 & 2 & 2\end{array}$

$\begin{array}{llllllllllllllllllll}\begin{array}{c}\text { cachexia } \\ \text { Without } \\ \text { cachexia }\end{array} & 54 & 38 & 25 & 21 & 12 & 7 & 6 & 5 & 3 & 2 & 1 & 1 & 1 & 1 & 1 & 1 & 1 & 1 & 1\end{array}$

Fig. 2 Overall survival according to presence or absence of follow-up cachexia within 12 (a), 24 (c), or 48 (e) weeks and at the landmark analyses at 12 (b), 24 (d), and 48 (f) weeks after the start of chemotherapy. CI confidence interval, MST median survival time

$(13.8-33.3) \mathrm{kg} / \mathrm{m}^{2}$, respectively. The Eastern Cooperative Oncology Group performance status (ECOG PS) scores were 0 in $70.7 \%$ and 1 in $29.3 \%$. The primary tumor sites were the pancreatic head (40.0\%) and body (42.0\%), and most patients had stage IV cancer (70.7\%). First-line chemotherapy was modified FOLFIRINOX (30.0\%), gemcitabine monotherapy $(38.0 \%)$, or gemcitabine + nabpaclitaxel (32.0\%). The median (range) albumin, CRP, and hemoglobin were $4.0(2.7-4.9) \mathrm{g} / \mathrm{dL}, 0.39(0.01-9.94) \mathrm{mg} /$ $\mathrm{dL}$, and 12.6 (8.1-18.2) g/dL, respectively. Base cachexia was found in 75 patients $(50.0 \%)$.

\section{Frequency and timing of follow-up cachexia}

Figure 1a shows the timing of follow-up cachexia onset. A total of $32.0 \%$ of patients experienced cachexia within 12 weeks of starting chemotherapy, while $13.3 \%$ experienced cachexia at 13-24 weeks, $10.7 \%$ at 25-36 weeks, and $8.0 \%$ at $37-48$ weeks. Figure $1 \mathrm{~b}$ shows the cumulative incidence of follow-up cachexia after the start of first-line chemotherapy. The cumulative incidence was $45.3 \%$ at 24 weeks, $64.0 \%$ at 48 weeks, and $71.3 \%$ over the full study period. Follow-up cachexia occurred during first-line chemotherapy in 65 
patients $(43.3 \%)$ (their characteristics are summarized in Table S1). Of 75 patients with base cachexia, 38 experienced follow-up cachexia during first-line chemotherapy (50.7\%), while the other 37 did not. Of 75 patients without base cachexia, 27 experienced follow-up cachexia during first-line therapy $(36.0 \%)$ (Table S1).

\section{Survival}

Figure 2 shows the OS for patients according to whether they experienced follow-up cachexia (or not) within 12 , 24 , or 48 weeks of starting chemotherapy. Within 12 weeks from the start of first-line chemotherapy, there was no difference in OS between patients with and without cachexia (Fig. 2a). The median survival time (95\% CI) was 370 (230-518) days for patients with cachexia versus 359 (306-474) days for patients without cachexia. There were no differences in OS between patients with or without cachexia when we divided the patients according to whether they experienced follow-up cachexia within 24 weeks (Fig. 2c) or 48 weeks (Fig. 2e) of starting chemotherapy. Landmark analyses were also done at these time-points. In the landmark analysis at 48 weeks, the median survival time in patients without follow-up cachexia (757 vs. 528 days) was slightly longer than that in patients with follow-up cachexia, although this was not statistically significant (log-rank $P=0.068$ ) (Fig. 2f). In the landmark analyses at 12 and 24 weeks, median OS was not significantly different between patients with or without cachexia (Fig. 2b, d). Follow-up cachexia occurring within 24 weeks of starting first-line chemotherapy was not a prognostic factor for OS in the unadjusted model (HR 1.12, 95\% CI $0.72-1.74, P=0.628$ ) or in the adjusted model (Table 2). CRP and multidrug therapy were prognostic factors for OS in the adjusted model. Base cachexia was not a prognostic factor for OS in the adjusted model.

\section{AEs in patients with or without follow-up cachexia}

Figure 3 shows the frequency, timing, and grade of AEs in patients with or without follow-up cachexia (cachexia occurring within 24 weeks after the start of first-line chemotherapy).

The rates of AEs were generally low at baseline (week 0) except for appetite loss, which was found in ca. $28 \%$ of patients with follow-up cachexia and $15 \%$ of patients without follow-up cachexia (Fig. 3a). As indicated in these figures, there were marked increases in the rate of grade $\geq 2 \mathrm{AEs}$, especially appetite loss (Fig. 3a), fatigue (Fig. 3b), nausea (Fig. 3c), and diarrhea (Fig. 3d), in patients with follow-up cachexia. The frequency and grade of rash and peripheral sensory neuropathy also tended to increase over time (Fig. 3e, f).

Anemia was reported in $57 \%$ of patients with follow-up cachexia (9\% with grade 2 and $49 \%$ with grade 1), and in $39 \%$ of patients without follow-up cachexia (6\% with grade 2 and 33\% with grade 1) (Fig. 3g). Thrombocytopenia and neutropenia AEs were rare at week 0 (Fig. 3h, i). There were marked increases in the frequencies and grades of anemia, thrombocytopenia, and neutropenia in patients with or without follow-up cachexia (Fig. 3g, h, i). The incidence of febrile neutropenia remained low throughout the follow-up period (Fig. 3j).

\section{Laboratory variables}

There was a small increase in CRP levels at 48 weeks in patients with follow-up cachexia (median change: $+0.280 \mathrm{mg} / \mathrm{dL}$ ) and in patients without (median change $+0.580 \mathrm{mg} / \mathrm{dL})$, which was significantly different $(P=0.044)$ (Table S2). There was a small decrease in albumin over the same period of time in both groups, with a median change of $-0.30 \mathrm{~g} / \mathrm{dL}$ in patients with follow-up cachexia and $-0.55 \mathrm{~g} / \mathrm{dL}$ in patients without follow-up cachexia. There
Table 2 Prognostic factors for overall survival by Cox proportional hazard model analysis

\begin{tabular}{lrr}
\hline & HR (95\% CI) & $P$ value \\
\hline $\begin{array}{l}\text { Presence of follow-up cachexia within 24 weeks of starting first-line } \\
\quad \text { chemotherapy (yes vs. no) }\end{array}$ & $1.12(0.70-1.79)$ & 0.637 \\
Age & $1.00(0.98-1.02)$ & 0.945 \\
Sex (female vs. male) & $1.18(0.75-1.85)$ & 0.480 \\
Multidrug therapy (vs. monotherapy) & $0.29(0.17-0.48)$ & $<0.001$ \\
ECOG PS (1 vs. 0) & $1.39(0.81-2.39)$ & 0.228 \\
UICC stage (IV vs. III) & $1.43(0.87-2.35)$ & 0.157 \\
CRP & $1.14(1.01-1.30)$ & 0.039 \\
Body weight loss at start of first-line chemotherapy (base cachexia; yes vs. no) & $1.18(0.74-1.87)$ & 0.495 \\
CA19-9 (positive vs. negative) & $0.97(0.58-1.63)$ & 0.920 \\
\hline
\end{tabular}

$H R$ hazard ratio, CI confidence interval, ECOG PS Eastern Cooperative Oncology Group performance status, UICC Union for International Cancer Control, CRP C-reactive protein, CA19-9 carbohydrate antigen 19-9 
a

Appetite loss

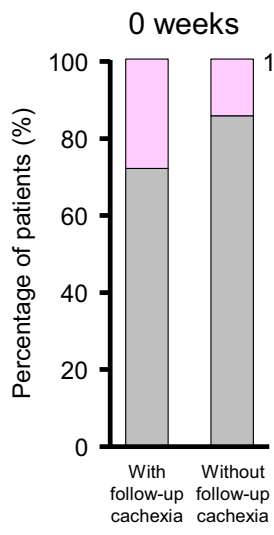

C

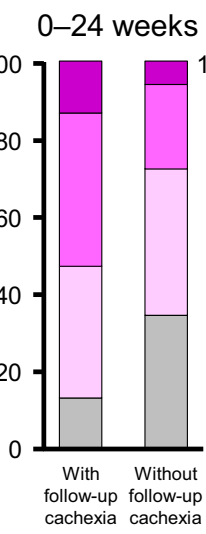

Nausea

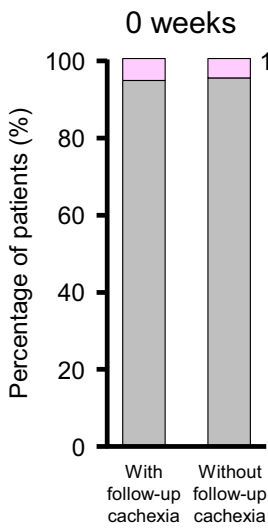

e
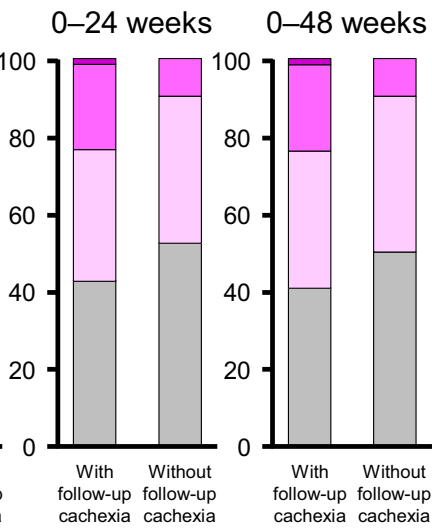

Rash

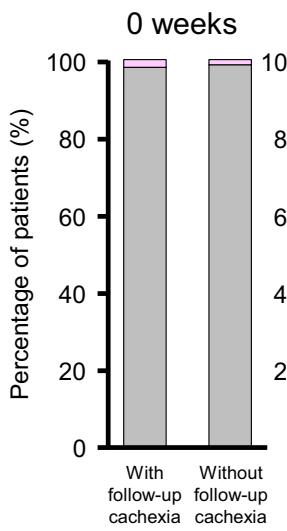

0-24 weeks

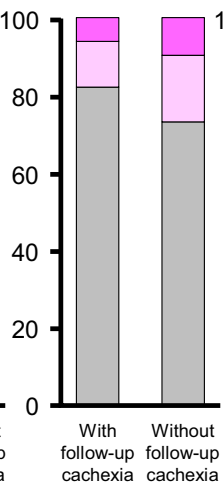

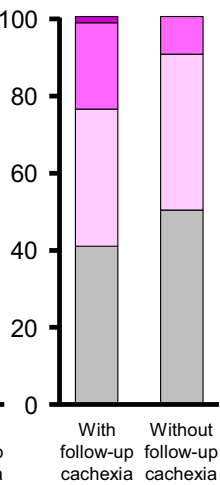

0-48 weeks

$0-48$ weeks

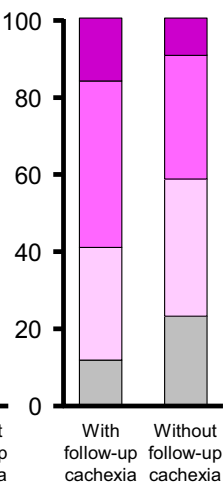

cachexia cachexia

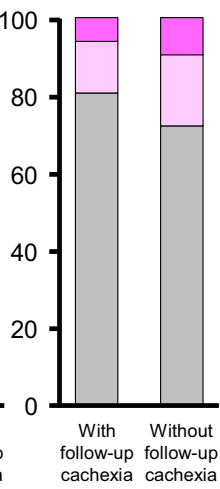

\section{Grade $1 \square$ Grade 2}

Fig. 3 Frequency and grade of adverse events in patients with or without follow-up cachexia up to 0,24 , or 48 weeks after starting first-line chemotherapy for the following adverse events: appetite loss (a),

were decreases in neutrophil and total lymphocyte counts in patients with follow-up cachexia, while the neutrophil count increased and total lymphocyte count decreased in patients b

Fatigue

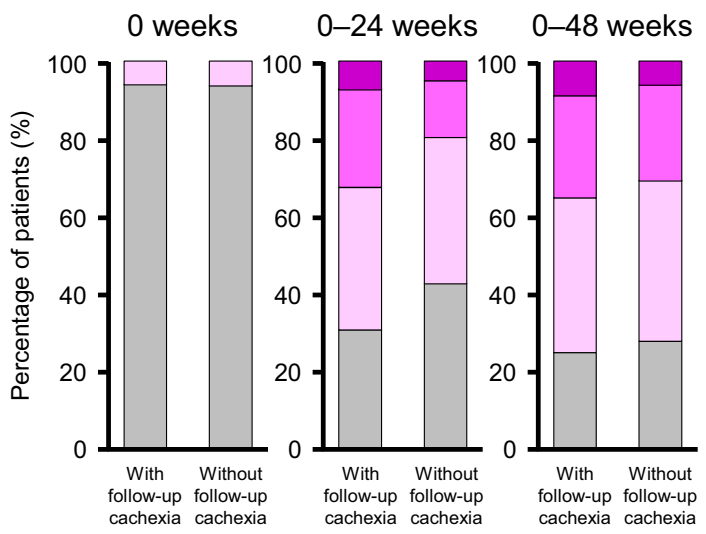

d

Diarrhea

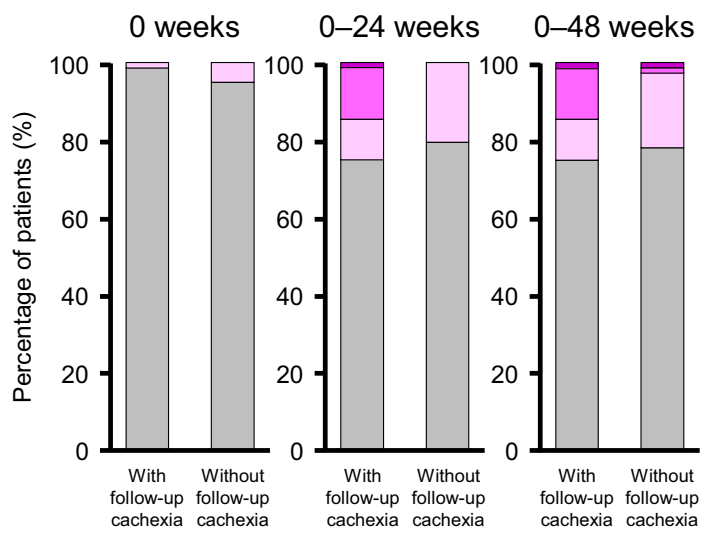

f

Peripheral sensory neuropathy

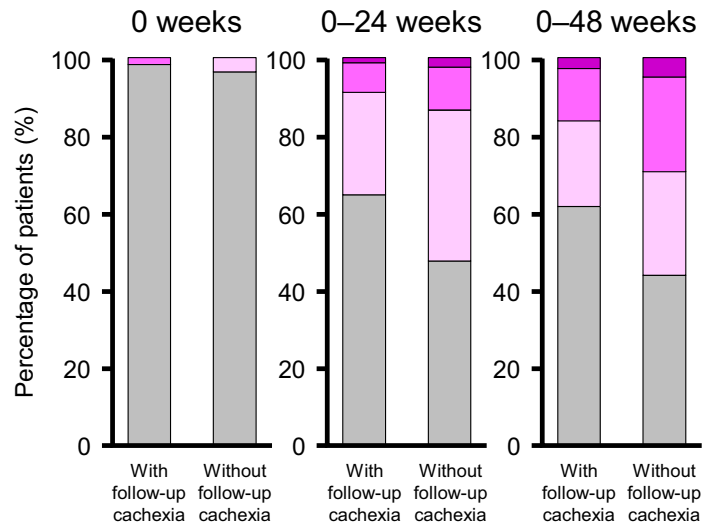

\section{Grade $3 \square$ Grade $4 \square$ None}

fatigue (b), nausea (c), diarrhea (d), rash (e), peripheral sensory neuropathy (f), anemia (g), thrombocytopenia (h), neutropenia (i), and febrile neutropenia $(\mathbf{j})$

without follow-up cachexia. Other than the change in CRP levels at 48 weeks, there were no significant differences in changes of these laboratory variables between the two groups. 


\section{g}

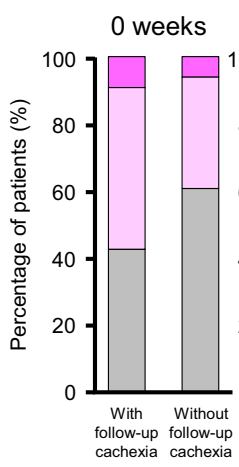

i

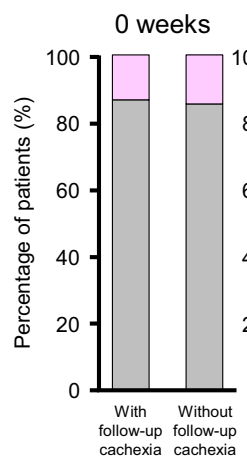

Grade 1

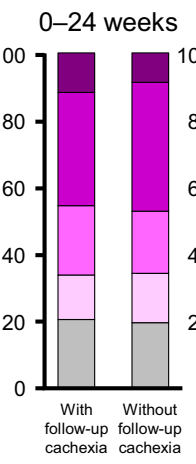

Anemia

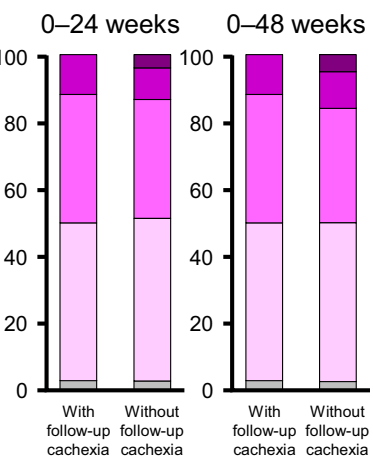

Neutropenia

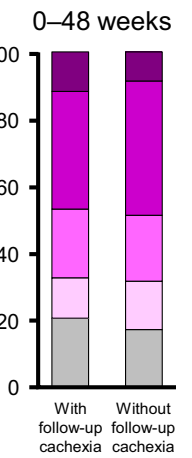

h

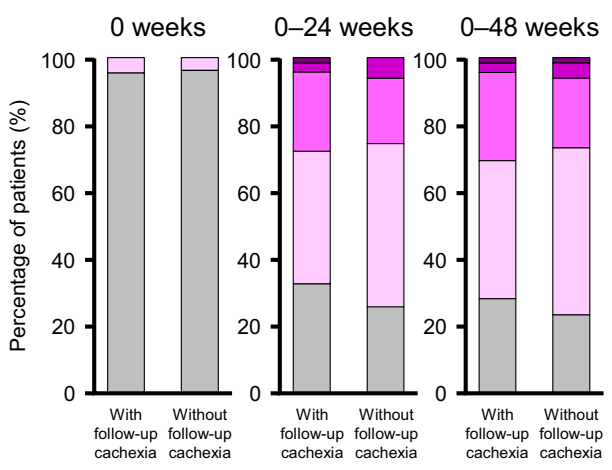

j

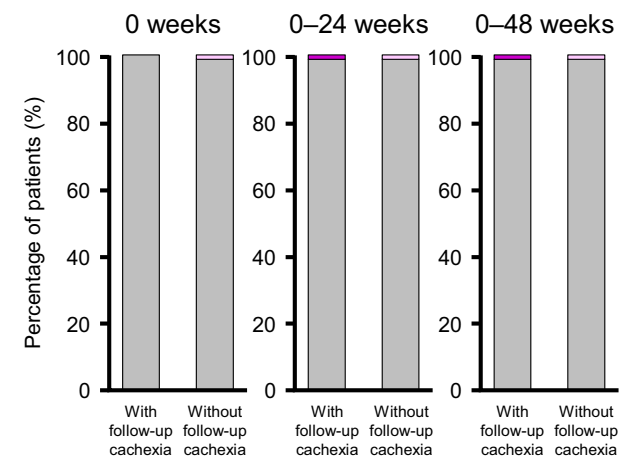

Fig. 3 (continued)

\section{Discussion}

Key findings of this study include the high rates of follow-up cachexia in patients with advanced pancreatic cancer, and that about one-third of patients experienced follow-up cachexia within 12 weeks of starting first-line chemotherapy, increasing up to $45 \%$ by 24 weeks. These findings are similar to those in a prior report of patients with lung cancer [13]. The cumulative incidence of follow-up cachexia was $71 \%$ over the study period. However, because deaths as a competing risk were not used to censor the analysis, the results suggest that all patients might experience follow-up cachexia.

The median survival time was not significantly different between patients with and without follow-up cachexia, regardless of whether cachexia occurred within 12, 24, or 48 weeks of starting first-line chemotherapy. This result was similar to the previous report in pancreatic cancer, although the definition of cachexia was different from this study [14]. In our study, we found that multidrug therapy (vs. monotherapy) was a significant prognostic factor. A recent study indicated that the effect of base cachexia on survival could be modulated by chemotherapy in patients with pancreatic cancer, although base cachexia was a significant prognostic factor [10]. These findings suggest that the survival benefit provided by chemotherapy may reduce the negative impact of follow-up cachexia on survival.

As expected, the frequency and grade of AEs tended to increase over time after starting first-line chemotherapy (Fig. 3). AEs were frequent in both patients with and without follow-up cachexia. Notably, the rates of some AEs with grade $\geq 2$, particularly appetite loss, fatigue, nausea, and diarrhea, were high in patients with follow-up cachexia, while the frequencies and grades of anemia, thrombocytopenia, and neutropenia showed similar increases in patients with and without cachexia. Although the cause-effect relationship between cachexia and the onset of appetite loss and fatigue is not fully clear, the higher frequency and grade of appetite loss and fatigue may interfere with the patient's ability to continue chemotherapy or affect the patient's wellbeing and quality of life. In a clinical trial in which patients were treated with gemcitabine + nab-paclitaxel for pancreatic cancer, it was reported that the treatment regimen was discontinued in $10 \%$ of patients due to an $\mathrm{AE}$ and in $20 \%$ of patients due to unacceptable toxicity [15]. In patients with gastrointestinal malignancies, it was reported that those experiencing weight loss generally had worse outcomes, partly because they received less chemotherapy and developed more toxicity [14]. Therefore, it is important to carefully monitor the body weight of patients during chemotherapy. 
We also noted that follow-up cachexia was relatively common in patients with base cachexia. This may reflect the high tendency for continuation of past weight loss after starting chemotherapy. Therefore, physicians should also pay attention to the changes in body weight that occurred before the start of chemotherapy.

Finally, in the present study, we adopted two EPCRC definitions because information on sarcopenia was unavailable. The cachexia criteria used here may not be generalizable to all patient populations or ethnic groups owing to differences in build, lifestyle, dietary habits, and background metabolic rate, for example [16]. Alternatively, it may be possible to use Evans' diagnostic criteria, which take account of inflammatory markers and poor appetite [17].

\section{Limitations}

A limitation of this study is that multiple first-line chemotherapy regimens were used, which affect OS and the rates/types of AEs. Thus, these regimens may have different associations with frequency or impact of cachexia. Other limitations include its retrospective single-center design and that base cachexia may influence the outcomes reported here. In addition, although we found a high rate of AEs during chemotherapy, the design of our study means we could not determine whether follow-up cachexia contributed to the onset and grade of the AEs, or vice versa.

\section{Conclusions}

In conclusion, the incidence of follow-up cachexia was highest within 12 weeks of starting first-line chemotherapy in this cohort of patients with advanced PDAC. Follow-up cancer cachexia occurred in $64 \%$ of patients within 48 weeks of starting first-line chemotherapy. However, it was not a prognostic factor for OS. The frequency and grade of appetite loss, fatigue, nausea, and diarrhea showed greater increases over time in patients with follow-up cachexia. Because we cannot exclude the possibility that the effects of chemotherapy, especially multidrug chemotherapy, overcame any negative effects of cancer cachexia itself, future studies may need to focus on individual chemotherapeutic regimens.

Acknowledgments This study was funded by Ono Pharmaceutical Co., Ltd. The authors thank DOT WORLD CO., LTD for organizing the study, data collection, and statistical analysis, and Nicholas D. Smith (EMC K.K.) for medical writing support, all of which were funded by Ono Pharmaceutical Co., Ltd. The authors also appreciate Dr. Koji Oba (The University of Tokyo) for his advice on statistical analysis.

Authors' contributions All authors conceived and designed the study, were responsible for study administration, and wrote and reviewed the manuscript. Shuichi Mitsunaga was the principal investigator and provided study resources. Shuichi Mitsunaga and Koji Machii supervised the study. Eiji Kasamatsu and Koji Machii were responsible for data handling and analysis. All authors reviewed and approved the final draft.

Data availability Qualified researchers may request Ono Pharma to disclose individual patient-level data from clinical studies through the following website: https://clinicalstudydatarequest.com/. For more information on Ono Pharma's Policy for the Disclosure of Clinical Study Data, please see the following website: https://www.ono.co.jp/ eng/rd/policy.html

\section{Compliance with ethical standards}

Conflict of interest Shuichi Mitsunaga has received research funds from Ono Pharmaceutical Co., Ltd. Eiji Kasamatsu and Koji Machii are employees of Ono Pharmaceutical Co., Ltd.

Open Access This article is licensed under a Creative Commons Attribution 4.0 International License, which permits use, sharing, adaptation, distribution and reproduction in any medium or format, as long as you give appropriate credit to the original author(s) and the source, provide a link to the Creative Commons licence, and indicate if changes were made. The images or other third party material in this article are included in the article's Creative Commons licence, unless indicated otherwise in a credit line to the material. If material is not included in the article's Creative Commons licence and your intended use is not permitted by statutory regulation or exceeds the permitted use, you will need to obtain permission directly from the copyright holder. To view a copy of this licence, visit http://creativecommons.org/licenses/by/4.0/.

\section{References}

1. Fearon K, Strasser F, Anker SD, Bosaeus I, Bruera E, Fainsinger RL, Jatoi A, Loprinzi C, MacDonald N, Mantovani G, Davis M, Muscaritoli M, Ottery F, Radbruch L, Ravasco P, Walsh D, Wilcock A, Kaasa S, Baracos VE (2011) Definition and classification of cancer cachexia: an international consensus. Lancet Oncol 12: 489-495. https://doi.org/10.1016/s1470-2045(10)70218-7

2. Baracos VE, Mazurak VC, Bhullar AS (2019) Cancer cachexia is defined by an ongoing loss of skeletal muscle mass. Ann Palliat Med 8:3-12. https://doi.org/10.21037/apm.2018.12.01

3. Bruggeman AR, Kamal AH, LeBlanc TW, Ma JD, Baracos VE, Roeland EJ (2016) Cancer cachexia: beyond weight loss. J Oncol Pract 12:1163-1171. https://doi.org/10.1200/jop.2016.016832

4. Escamilla DM, Jarrett P (2016) The impact of weight loss on patients with cancer. Nurs Times 112:20-22

5. Lau SKM, Iyengar P (2017) Implications of weight loss for cancer patients receiving radiotherapy. Curr Opin Support Palliat Care 11: 261-265. https://doi.org/10.1097/spc.0000000000000298

6. Tarricone R, Ricca G, Nyanzi-Wakholi B, Medina-Lara A (2016) Impact of cancer anorexia-cachexia syndrome on health-related quality of life and resource utilisation: a systematic review. Crit Rev Oncol Hematol 99:49-62. https://doi.org/10.1016/j. critrevonc.2015.12.008

7. Dewys WD, Begg C, Lavin PT, Band PR, Bennett JM, Bertino JR, Cohen MH, Douglass HO Jr, Engstrom PF, Ezdinli EZ, Horton J, Johnson GJ, Moertel CG, Oken MM, Perlia C, Rosenbaum C, Silverstein MN, Skeel RT, Sponzo RW, Tormey DC (1980) Prognostic effect of weight loss prior to chemotherapy in cancer patients. Eastern Cooperative Oncology Group. Am J Med 69:491497. https://doi.org/10.1016/s0149-2918(05)80001-3 
8. Blum D, Omlin A, Fearon K, Baracos V, Radbruch L, Kaasa S, Strasser F (2010) Evolving classification systems for cancer cachexia: ready for clinical practice? Support Care Cancer 18:273279. https://doi.org/10.1007/s00520-009-0800-6

9. Takayama K, Atagi S, Imamura F, Tanaka H, Minato K, Harada T, Katakami N, Yokoyama T, Yoshimori K, Takiguchi Y, Hataji O, Takeda Y, Aoe K, Kim YH, Yokota S, Tabeta H, Tomii K, Ohashi Y, Eguchi K, Watanabe K (2016) Quality of life and survival survey of cancer cachexia in advanced non-small cell lung cancer patientsJapan nutrition and QOL survey in patients with advanced nonsmall cell lung cancer study. Support Care Cancer 24:3473-3480. https://doi.org/10.1007/s00520-016-3156-8

10. Hendifar AE, Chang JI, Huang BZ, Tuli R, Wu BU (2018) Cachexia, and not obesity, prior to pancreatic cancer diagnosis worsens survival and is negated by chemotherapy. J Gastrointest Oncol 9:17-23. https://doi.org/10.21037/jgo.2017.11.10

11. Sanchez-Lara K, Ugalde-Morales E, Motola-Kuba D, Green D (2013) Gastrointestinal symptoms and weight loss in cancer patients receiving chemotherapy. Br J Nutr 109:894-897. https://doi. org/10.1017/s0007114512002073

12. National Institutes of Health National Cancer Institute. Common Terminology Criteria for Adverse Events (CTCAE) Version 4.0. 2009. Available from URL: https://evs.nci.nih.gov/ftp1/CTCAE/ About.html [accessed October 3, 2018]

13. Kimura M, Naito T, Kenmotsu H, Taira T, Wakuda K, Oyakawa T, Hisamatsu Y, Tokito T, Imai H, Akamatsu H, Ono A, Kaira K, Murakami H, Endo M, Mori K, Takahashi T, Yamamoto N (2015) Prognostic impact of cancer cachexia in patients with advanced non-small cell lung cancer. Support Care Cancer 23: 1699-1708. https://doi.org/10.1007/s00520-014-2534-3

14. Andreyev HJ, Norman AR, Oates J, Cunningham D (1998) Why do patients with weight loss have a worse outcome when undergoing chemotherapy for gastrointestinal malignancies? Eur J Cancer 34: 503-509. https://doi.org/10.1016/s0959-8049(97)10090-915

15. Von Hoff DD, Ervin T, Arena FP, Chiorean EG, Infante J, Moore M, Seay T, Tjulandin SA, Ma WW, Saleh MN, Harris M, Reni M, Dowden S, Laheru D, Bahary N, Ramanathan RK, Tabernero J, Hidalgo M, Goldstein D, Van Cutsem E, Wei X, Iglesias J, Renschler MF (2013) Increased survival in pancreatic cancer with nab-paclitaxel plus gemcitabine. N Engl J Med 369:1691-1703. https://doi.org/10.1056/NEJMoa1304369

16. Konishi M, Ishida J, Springer J, Anker SD, von Haehling S (2016) Cachexia research in Japan: facts and numbers on prevalence, incidence and clinical impact. J Cachexia Sarcopenia Muscle 7:515519. https://doi.org/10.1002/jcsm.12117

17. Evans WJ, Morley JE, Argiles J, Bales C, Baracos V, Guttridge D, Jatoi A, Kalantar-Zadeh K, Lochs H, Mantovani G, Marks D, Mitch WE, Muscaritoli M, Najand A, Ponikowski P, Rossi Fanelli F, Schambelan M, Schols A, Schuster M, Thomas D, Wolfe R, Anker SD (2008) Cachexia: a new definition. Clin Nutr 27:793799. https://doi.org/10.1016/j.clnu.2008.06.013

Publisher's note Springer Nature remains neutral with regard to jurisdictional claims in published maps and institutional affiliations. 